\title{
Trabalho, carreira, desenvolvimento docente e mudança na prática educativa
}

Claudio Pinto Nunes

Dalila Andrade Oliveira"

\begin{abstract}
Resumo
0 artigo propõe-se a discutir algumas questões encontradas na literatura recente sobre a profissão docente, nas condições de trabalho do professor, no desenvolvimento profissional, na carreira e na mudança na prática educativa. Esses pontos são tomados como basilares para a análise da melhoria e da mudança na escola, tanto no que diz respeito à melhoria da qualidade da aprendizagem pelos estudantes da educação básica quanto em relação aos aspectos relevantes para o decorrente avanço social que tais estudantes possam apresentar em face daquilo que aprenderam na educação básica. 0 texto defende uma maior articulação entre políticas públicas educacionais e trabalho docente, de modo que o professor não seja responsabilizado pelo fracasso ou sucesso da aprendizagem dos estudantes. Tal defesa decorre do entendimento de que as mudanças por que vêm passando as sociedades fazem com que haja a necessidade de uma escola cada vez mais atenta às demandas de seu tempo, com desenvolvimento profissional do professor e com qualidade das condições de exercício da docência.
\end{abstract}

\section{Palavras-chave}

Profissão docente - Condições de trabalho do professor Desenvolvimento profissional docente - Carreira docente - Prática docente.

I- Universidade Estadual do Sudoeste da Bahia, 


\title{
Work, career, teaching development, and change in educational practice
}

Claudio Pinto Nunes

Dalila Andrade Oliveira"

\begin{abstract}
This article aims to discuss some issues found in recent literature on the teaching profession, the teachers' working conditions, professional development, career, and change in educational practice. These points are taken as fundamental to the analysis of the improvement and change in school, with regards both to improvement in student learning in primary education, and to the relevant aspects of the possible social advancement of such students in the face of what they learned in primary education. The text advocates a greater coordination between public educational policy and teaching practice, so that teachers are not held responsible for the failure or success of student learning. This argument stems from the understanding that current changes in societies lead to the need for a school that is increasingly attentive to the demands of its time, with the teacher professional development and quality conditions for teaching.
\end{abstract}

\section{Keywords}

Teaching profession - Teachers' working conditions - Teaching professional development - Teaching career - Teaching practice.

I- Universidade Estadual do Sudoeste da Bahia, Vitória da Conquista, BA, Brasil.

Contact: claudionunesba@hotmail.com

II- Universidade Federal de Minas Gerais, Belo Horizonte, MG, Brasil.

Contact: dalilaufmg@yahoo.com.br 
Este artigo pretende desenvolver uma análise acerca da profissão docente no contexto social contemporâneo, em que ocorrem muitas mudanças de natureza tecnológica e econômica, com implicações e exigências diretas para a escola. Pretende-se realizar uma discussão sobre o desenvolvimento profissional docente em face das exigências e das mudanças às quais o professor é impelido a responder. Com base em algumas leituras (VALLANT et al., 2009) que têm apontado para mudanças em relação à formação e à carreira e apresentam o desenvolvimento profissional docente como um novo conceito que tem sido incorporado às políticas docentes, este texto procura desenvolver uma reflexão sobre os possíveis efeitos desses processos na prática educativa na escola básica.

Ressalta-se, entretanto, que, ao focar a educação básica como referência de análise, não significa que as dimensões do trabalho docente aqui referidas sejam exclusivas desse nível de escolaridade. É sabido que não somente o ensino superior apresenta suas especificidades, como, também, dentro da própria educação básica há diferenças na organização e nas condições de trabalho, quando analisada cada etapa em suas próprias especificidades. Neste texto, as discussões se referem especialmente aos docentes envolvidos na educação básica escolar.

A base metodológica para a produção deste artigo está fundamentada em referenciais teóricos que refletem sobre diferentes ângulos da questão analisada, sendo, portanto, um estudo de natureza exploratória e de cunho bibliográfico. Há, nesse sentido, olhares de diferentes autores em torno de perspectivas que se coadunam na defesa de condições favoráveis para o desenvolvimento da educação, do profissional e da carreira docente, além do avanço na melhoria da qualidade da educação, por entender que, sem que ocorra um percurso progressivo no nível de produção do conhecimento na escola, junto aos estudantes, todo o investimento, financeiro e científico, feito em educação carece de sentido.

\section{A profissão docente e as mudanças no contexto da contemporaneidade}

As constantes mudanças que o mundo viveu nas últimas décadas, sobretudo no que se refere ao desenvolvimento científico e tecnológico, com significativa transformação da base econômica, não têm sido assimiladas significativamente pelas instituições formadoras de professores, no sentido de propor e oferecer uma formação inicial mais articulada com as transformações da sociedade. Segundo Esteve (2009, p. 22):

[...] nuestra sociedad exige que los profesores asuman estos nuevos papeles, no se ha cambiado la formación inicial que los profesores receben para hacer frente a estas nuevas exigências.

Para o autor, ocorre um movimento de desenvolvimento mais acelerado em outros setores da sociedade do que no setor educacional. São muitas as razões que explicam esse descompasso entre o que se oferece na formação inicial de professores e as exigências cotidianas do trabalho escolar, contudo, afirmações generalizantes não contribuem para a resolução do problema. Pesquisas têm evidenciado que os professores se sentem pouco preparados para o início da sua inserção profissional (TALLIS, 2013; OLIVEIRA; VIEIRA, 2010; GATTI; BARRETO, 2009), mas, no caso brasileiro, é necessário observar que as condições de formação docente variam muito de acordo com a natureza das instituições que a ofertam (OLIVEIRA, 2013).

Esteve chama a atenção para a necessidade de o professor desenvolver competência social para que este se sinta capaz de assumir as situações conflituosas provenientes das mudanças sociais de cada tempo histórico. Para tanto, há de se pensar e propor estratégias desde a formação inicial (e também no exercício da profissão, por meio da formação continuada) acerca das mudanças sociais e da consequente 
exigência de formação profissional docente, de modo a preparar o futuro professor (e o professor já inserido no exercício da profissão) para enfrentar os conflitos próprios de cada momento/fase do processo de mudança social.

Se não houver constante qualificação docente, o professor pode perder o entusiasmo pela profissão. Acredita-se que sem a realização de estudos sistemáticos com vista ao desenvolvimento profissional, o professor não consegue estabelecer e manter a capacidade de analisar as mudanças educativas, além de ter dificuldade de adaptar-se às novas exigências da educação contemporânea.

Esteve (2009) apresenta dez indicadores básicos para resumir as principais mudanças da educação nos últimos anos:

a) Novas responsabilidades para o professor (o professor tem de ser facilitador/ problematizador da aprendizagem, organizador do trabalho, além de ter de atender ao ensino, cuidar do equilíbrio psicológico e afetivo de seus alunos, da integração social etc.), embora não tenha ocorrido mudança na formação para essas novas responsabilidades; ou, quando ocorreu, não acompanhou o mesmo ritmo ou intensidade.

b) Com a redução das responsabilidades de outros agentes sociais, como a família, sobre suas funções educativas, tal tarefa tem sido atribuída quase exclusivamente ao professor. No entanto, paulatinamente, há de se abandonar essas responsabilidades fora da escola.

c) Compreensão pelo professor da internet e dos meios de comunicação como fontes de informação alternativas, as quais ele precisa incorporar à sua dinâmica de trabalho. Não se pode esquecer de que muitos estudantes acompanham os avanços das tecnologias da comunicação e da informação com muito mais propriedade do que o fazem alguns professores.

d) A diversificação dos valores a serem ensinados/aprendidos na escola exige que o professor atue tendo em vista os diferentes modelos educativos na sociedade plural (da socialização convergente à socialização divergente). Se antes a escola absorvia as classes alta e média, atualmente, com as políticas públicas de universalização do acesso à escola, esta tem ampliado sua abrangência para as camadas populares, fazendo com que a sala de aula passe a ser entendida como um espaço plural. Essa situação exige do professor mudanças no entendimento, na prática e na gestão pedagógica de suas aulas, de modo a desenvolver uma educação que atenda à diversidade de aspectos culturais presentes numa mesma sala. 0 professor precisa incorporar em suas aulas uma postura sensível a questões de natureza linguística e cultural muito diversas, posto que os alunos provêm de contextos sociais com educação familiar em que os valores são igualmente distintos.

e) A diversificação da sociedade com diferentes modelos ou diferentes culturas obriga o professor a se preparar na busca de equilíbrio ante os modelos educativos contracorrentes, observando não apenas a diversidade cultural, mas também atendendo às determinações provenientes das novas legislações que surgem em resposta às demandas da própria pluriculturalidade.

f) A mudança na rentabilidade social da educação, em que professores, alunos e pais devem entender que a escola pode proporcionar a formação e o desenvolvimento do cidadão na sociedade contemporânea, mas não constitui o status social que oferecia no passado.

g) 0 juizo social do professor e a critica generalizada ao sistema de ensino. No passado, os pais e a sociedade, em geral, apoiavam os professores em relação às dificuldades do processo educativo, atualmente defendem os alunos/filhos. Nas palavras de Esteve (2009, p. 25), "si todo va bien, los padres piensan que sus hijos son buenos estudiantes, pero si van mal, piensan que los profesores son malos docentes".

h) A consideração social do professor em sua sociedade materialista como uma questão ideológica. No mesmo ritmo em que ocorre uma desconsideração salarial do professor, há também a desvalorização profissional docente. 
A posição ocupada pelo professor na sociedade atual termina por absorver as representações que são estabelecidas sobre este ramo profissional tanto por outros sujeitos sociais como pelo próprio professor. 0 resultado disso, entre outras coisas, pode reverberar na construção de uma identidade profissional docente.

i) A necessidade de revisar os conteúdos curriculares em face do avanço das ciências e da variação das demandas sociais, de modo a garantir que, ao mesmo tempo em que a escola priorize em seus conteúdos o crescimento econômico do país, tenha lugar também o desenvolvimento social dos cidadãos. Ao se entender que o conteúdo é um dos elementos centrais na composição de uma aula, esperase que o professor esteja atualizado, teórica e metodologicamente, sobre as inovações científicas por que passa o conteúdo em sua própria área e nas interfaces com as diferentes áreas do conhecimento científico.

j) Autoridade e disciplina na relação educativa. Se no passado o professor era considerado o detentor de todo o poder dentro da sala de aula em detrimento dos estudantes, atualmente essa situação se inverteu, chegando a causar, em alguns contextos escolares, muitos conflitos entre professor e alunos, com agressões verbais e físicas (ESTEVE, 2009).

Mesmo variando de acordo com o nível de escolarização em que atua o professor, muitas vezes, esta inversão termina por exigir do professor outras (novas) formas de enfrentamento no que se refere às questões da dinâmica do cotidiano do trabalho docente.

Sem dúvida, esses indicadores de mudança identificados por Esteve (2009) têm implicações para o trabalho, para a carreira, para o desenvolvimento profissional e para a qualidade da educação oferecida pela escola básica. Ainda que o autor tenha como referência o contexto europeu, esta realidade também pode ser observada na região latino-americana e mais especificamente no Brasil.

Nessa região, os movimentos de democratização da educação manifestaram- se por maior participação na gestão escolar e pedagógica. Um exemplo disso foi o que ocorreu a partir dos anos 1980 com o movimento da didática em questão (CANDAU, 1983), em que no centro da discussão estava o reconhecimento da falsa neutralidade do professor e da possibilidade do desenvolvimento de práticas pedagógicas, que tivessem como orientação principal a observância das finalidades sociais e políticas da educação escolar.

Ao reivindicar como parte do processo de escolarização a dimensão social e política da prática educativa, reconhece-se, por consequência, a redefinição dos fins sociais da educação. Essas reivindicações, somadas ao desenvolvimento científico e tecnológico das últimas décadas, exige a revisão dos currículos tanto da educação básica, como dos próprios cursos de formação de professores, o que, desde a última década, vem sofrendo atualizações, de modo a contemplar as demandas advindas do contexto local em que cada escola se insere, como, por exemplo, políticas afirmativas, acesso e inclusão de pessoas com diferentes características físicas, sociais e intelectuais e as mudanças mais amplas ocorridas no plano internacional.

Nos países latino-americanos, que após pelo menos uma década de reformas neoliberais, puderam viver a experiência de novos governos democráticos, como Argentina, Brasil, Uruguai, Venezuela, Equador, Bolívia, entre outros, os processos de democratização da sociedade incidiram sobre a educação. Esses processos se caracterizaram por uma redefinição da escola como campo de realização da escolarização, pela constatação da necessária melhoria nas estruturas físicas das escolas e dos recursos didático-pedagógicos. No âmbito da formação de professores, a despeito da grande diversidade de modelos que convivem nos diferentes países da região, o momento assinala uma defesa pela formação em nível superior para os docentes independentemente da etapa e do nível de ensino em que atuam (PASEM, 2013).

No entanto, as demandas para a formação docente na atualidade são amplas e bastan- 
te complexas. Desde as expectativas descritas no Relatório Talis da OCDE do que deveria ser um bom docente aos indicadores apresentados por Esteve (2009), são desafios nada fáceis e que dependem de condições políticas que não estão dadas em muitos países. As referidas expectativas resultam num conjunto de necessidades para a atuação profissional do professor e para a sua formação que é demasiadamente amplo. Tais expectativas dizem respeito à identidade profissional, à necessidade de melhorias na formação inicial (considerando-se a profissionalização) e na formação continuada (considerando-se o desenvolvimento profissional), à carência de valorização da profissão docente, ao desenvolvimento de capacidades profissionais e atitudinais que impactam diretamente sobre sua identidade profissional e sua relação com trabalho.

\section{A carreira e o desenvolvimento profissional docente}

De acordo com Oliveira (2009), o desenvolvimento profissional surge nas políticas educativas da atualidade como um imperativo, a necessidade dos professores buscarem permanentemente melhorias no seu desempenho, na sua atuação. 0 desenvolvimento profissional, tomado como um modelo estratégico de formação, assume o lugar de "uma nova cultura profissional, forjada nos valores da colaboração e do progresso social, considerado como transformação educativa e social" (RAMALHO, 2004, p. 65). A despeito de que em alguns casos a noção de desenvolvimento profissional estar associada à possibilidade de progresso na vida profıssional, levando em consideração outros fatores que não só a formação continuada: salário, condições de trabalho etc.; o peso atribuído à formação é preponderante. Observa-se um forte acento da literatura específica na noção de formação como condição de tal desenvolvimento, como um projeto coletivo, colaborativo e crítico-reflexivo, em que o desenvolvimento profissional é ao mesmo tempo desenvolvimento institucional. A formação continuada é apresentada como sinônimo de desenvolvimento profissional ao longo da vida, único fator capaz de justificar e pôr em movimento os outros componentes que conduzem à profissionalização. A construção da profissão docente estaria assim dada, sobretudo, pela formação concebida como a possibilidade de aprendizagem permanente. Trata-se de uma abordagem em geral normativa, que estabelece o desenvolvimento profissional e institucional como faces da mesma moeda e que atribui à consciência do profissional a possibilidade de mudança ética na educação. Os professores são, em última instância, os responsáveis por seu desenvolvimento profissional, que deve ser tomado como um dever e obrigação para a melhoria da educação em geral, ou seja, passa-se para o professor a responsabilidade de gerir sua trajetória profissional (OLIVEIRA, 2009).

Na perspectiva de Vaillant (2009), para se promover o desenvolvimento profissional docente com impactos na sala de aula, três processos são fundamentais: a) boa proposta de inovação com um adequado respaldo social às transformações que se realizam no exercício da atividade docente; b) recursos materiais; e c) certa continuidade que permita que as mudanças se mantenham ao longo do tempo. Como ressalta a autora, é preciso vontade política e consensos, tendo em vista a variedade de posicionamentos presentes em toda instituição escolar ou sistema educacional.

Vontade política e consensos encontram dificuldades no sentido de definir o lugar das políticas para o desenvolvimento profissional docente na agenda administrativa dos governos (na definição de prioridades, posto que muitas políticas são originadas nos Ministérios da Educação de cada país e deixadas de lado ao surgirem novas prioridades); na rivalidade entre as pessoas que compõem as equipes responsáveis por elaborar e que tomam frente na proposição dessas políticas (divergência de entendimentos e de interesses, sobretudo quando há participação social); e no processo de negociação com os sindicatos (as políticas 
definidas pelo poder público, em muitos aspectos, não se coadunam com os interesses dos sindicatos, como categoria profissional). Contudo, sabemos que vontade política e consensos são categorias que apresentam pouca objetividade para a análise.

Muitas vezes, o resultado da relação entre vontade política e consensos, como ressalta Vaillant (2009), é uma não correspondência entre os recursos investidos e os impactos na sala de aula. Com isso, muitas ações previstas nos projetos educacionais terminam não saindo do papel, comprometendo, muitas vezes, os bons resultados das políticas.

Essa mesma autora advoga que, para que ocorra o desenvolvimento profissional docente, não bastam políticas parciais de governo, sendo necessárias políticas de Estado com estratégias sistêmicas de ação.

El proceso de formulación de políticas educativas para un desarrollo profesional docente "que sirva" debería entenderse como un proceso continuo y unitario que comience con el desarrollo de objetivos, defina estrategias para conseguirlos y establezca planes coherente con las decisiones; esto es, que decida por adelantado cuestiones como: ¿qué se hará? Pero también deberá incorporar mecanismos que permitan las adaptaciones necesarias que las nuevas realidades impongan. (VAILLANT, 2009, p. 35).

Nesse contexto, as políticas de desenvolvimento profissional docente precisam garantir um atrativo maior para a profissão, a fim de que os professores não a abandonem depois de amplo processo formativo. É necessária uma valorização docente de modo a fomentar um imaginário coletivo acerca da profissão, desenvolvendo ações concretas de melhoras das condições de trabalho e, ao mesmo tempo, a proposição de mecanismos avaliadores e reguladores para garantir a responsabilidade dos docentes no exercício da profissão. Também é imprescindível a defınição de plano de cargos e salários com uma apropriada estrutura de remuneração, incentivos e promoções de acordo com o percurso formativo e trajetória histórica de atuação do professor. No caso brasileiro, sabemos que, apesar da Resolução 02/2009 do Conselho Nacional de Educação, que trata das Diretrizes Nacionais da Carreira dos Profissionais do Magistério, e da Lei 11.738/2008, que institui o Piso Salarial Profissional Nacional, ambas normativas em âmbito federal, não têm tido a força necessária para ser cumpridas nos estados e municípios que compõem a federação.

A atratividade da carreira docente é hoje uma questão preocupante no mundo. Os processos de desvalorização e desprofissionalização docente têm impactado a procura por essa carreira (DUARTE, 2013; MORICONI, 2008; LEME, 2011). Diante dessa constatação, algumas políticas começam a ser pensadas premidas pelos riscos colocados. As preocupações vão no sentido de possibilitar uma carreira docente que seja atrativa aos jovens, evitando que apenas aqueles que não conseguem bons resultados nos cursos de reconhecimento social se dediquem aos cursos de licenciatura e assumam as funções da docência sem, de fato, terem escolhido esta profissão como parte de seus projetos pessoais e de vida. Para alguns autores (VAILLANT, 2009; GATTI; BARRETO, 2009; ANDRÉ, 2011), para o desenvolvimento profissional docente, são necessárias estratégias sistêmicas de ação que levem em conta as demandas de cada contexto e não políticas parciais.

Observa-se, na literatura mais recente, que alguns estudos têm tentado compreender as razões da baixa atratividade e da insatisfação para com a carreira docente apresentando diferentes elementos para a discussão. Nesses estudos o desenvolvimento profissional docente aparece como um elemento importante. Terigi (2009) chama a atenção para uma característica marcante da carreira docente no que se refere à vinculação com o desenvolvimento profissional. Conforme essa autora, as carreiras, sejam aquelas 
definidas nos planos de cargos dos sistemas de ensino, sejam aquelas traçadas na dinâmica das negociações políticas ou das próprias necessidades das diferentes redes de oferta de escolarização, permitem que o docente ascenda a postos de trabalho que o distanciam das atividades em sala de aula. Na compreensão dela, a configuração dessa mobilidade profissional faz entender que os bons professores, aqueles que conseguem um considerável desenvolvimento profissional, são premiados com postos de atuação profissional dentro da área de educação, mas distante do campo de trabalho mais direto do professor, que é a sala de aula, no convívio cotidiano com os estudantes.

Nesse sentido, ocorre uma contradição que pode ser compreendida pela existência, nesse contexto, de duas condições. A primeira diz respeito ao fato de não haver mecanismo de promoção dentro de um mesmo cargo, ou seja, de o professor ser promovido na carreira docente, sendo reconhecido socialmente $\mathrm{e}$ respeitado financeiramente, e permanecer atuando em sala de aula.

Por outro lado, observa-se que há a criação de cargos diversos para cada atividade. Esses cargos (ou postos de trabalho) é que são diferentemente remunerados, de modo que as pessoas tendem a querer, muitas vezes, sair da sala de aula para conseguir ascender a melhores remunerações.

Observadas essas contradições, e considerando-se os planos de cargos e salários em diferentes localidades, sobretudo no contexto brasileiro pós-LDB (BRASIL, 1996), percebe-se que normalmente os cargos é que são mais ou menos remunerados e não as pessoas, respeitados os seus percursos formativos e suas trajetórias de qualificação em busca do desenvolvimento profissional docente. Isso, entre outras coisas, acaba por comprometer, ainda, o interesse do professor em se qualificar ou desenvolver processos de desenvolvimento profissional, tendo em vista que, em muitos contextos ou redes de ensino, tais processos não repercutem em promoção ou avanços no exercício da profissão. Contudo, sabemos que esta é uma questão polêmica e de difícil resolução sem que se corra o risco de cair no individualismo competitivo.

Outro problema apontado em relação à carreira docente na literatura é que a principal diferença na remuneração entre docentes está relacionada ao tempo de serviço do professor e não ao desenvolvimento profissional (JACOMINI; MINHOTO, 2012; BARBOSA FILHO; PESSÔA; AFONSO, 2009). Mesmo quando há a valorização pontual da participação do professor em programas de formação continuada, essa valoração diz respeito ao tempo de participação nesses programas e não ao conteúdo aprendido/ construído neles. Ou seja, a presença prevalece em relação às aprendizagens decorrentes. Embora se saiba que o mais importante é o que se apreende nesses processos de formação, esta não deixa também de ser uma questão polêmica, pois levada ao extremo, poderia engendrar processos de avaliação ou medição de aprendizagens nos processos de formação continuada de professores, a exemplo do que tem sido realizado com os estudantes no Brasil.

Ao tratar sobre a formação do professor, Terigi (2009) faz referência a cinco problemas para as políticas de desenvolvimento profissional docente: a) a formação inicial como base para o desenvolvimento (há muitos professores em exercício da profissão sem a formação inicial exigida, embora as políticas atuais estejam mudando consideravelmente esta situação, especialmente no Brasil, onde nos últimos quinze anos foi invertida a proporção de professores com títulos, em 1996 apenas 25\% dos professores em exercício na educação básica tinham um diploma de curso superior, na atualidade são mais de $75 \%$ os que detém esse título); b) os saberes docentes (não se dispõe de um marco referencial adequado, nem de uma teoria suficientemente provada acerca do modo como os novos saberes se incorporam ao marco referencial dos docentes); c) a inversão sustentada na formação inicial (a articulação entre carreira docente e 
desenvolvimento profissional é provisória, sobretudo devido aos recursos destinados serem insuficientes e tal articulação não ser priorizada nas políticas públicas); d) as condições de trabalho dos docentes e as perspectivas de formação continuada (a falta de estrutura física e administrativa na escola dificulta que o professor tenha tempo disponível para se dedicar à aprendizagem, além de as próprias condições de trabalho fazerem com que muitos professores desacreditem os benefícios da formação continuada, sobretudo quando já exercem a profissão há um tempo maior); e) o conflito potencial das iniciativas de desenvolvimento profissional docente e os propósitos da categoria profissional (as propostas governamentais para o desenvolvimento profissional não atendem à expectativa dos sindicatos; mesmo quando o diálogo acontece, os consensos são raros).

Tratando de forma mais específica sobre desenvolvimento profissional docente, Marcelo (2009) chama a atenção para este conceito, posto que a literatura especializada utiliza outros termos para se referir à mesma situação. Assim, são empregadas nomenclaturas como formação permanente, formação continuada, formação em serviço, desenvolvimento de recursos humanos, aprendizagem ao longo da vida, reciclagem ou capacitação.

0 termo desenvolvimento profissional docente apresenta o entendimento de processo ininterrupto, que supera a ideia de justaposição entre formação inicial e aperfeiçoamento dos professores, conforme ressalta Marcelo (2009).

Para o mesmo autor, o desenvolvimento profissional docente se caracteriza por uma atitude permanente de indagação, de proposição de perguntas e problemas e de busca de suas soluções, sendo, portanto, uma ferramenta imprescindível para a melhora tanto da escola como do profissional.

El desarrollo profesional docente es una herramienta imprescindible para la mejora escolar y profesional. Estamos lejos de los momentos en los que se pensaba que el bagaje de conocimientos adquiridos en la formación inicial, unido al valor de la experiencia como fuente de aprendizaje en la práctica, podía resultar suficiente para ejercer el trabajo de docente. Los vertiginosos cambios que se están produciendo en nuestras sociedades nos inducen a creer que el desarrollo profesional, lejos de ser una cuestión voluntarista y casual, se ha convertido en una necesidad de cualquier profesional, incluidos los docentes. (MARCELO, 2009, p. 119).

Entretanto, é preciso considerar que, muitas vezes, a formação profissional docente tem mais impactos no salário do professor e pouca influência em seu desempenho profissional e na aprendizagem pelo docente e, por conseguinte, pelos seus estudantes inseridos no cotidiano da escola básica, como resultado do processo de formação de professor.

Cuando las actividades de formación se conceptualizan pobremente, no son sensibles a las preocupaciones de los participantes; no hay relación entre las experiencias de aprendizaje y las condiciones laborales de trabajo; y además la formación tiene poco impacto en los profesores y en sus estudiantes. (MUIJS, 2004 apud MARCELO, 2009, p. 120).

Programas de desenvolvimento profissional docente que partem da concepção de que o desenvolvimento poderá ocorrer a partir de cursos/capacitações esporádicas, sem sequência, promovidos por especialistas sem a participação direta dos professores no processo de idealização, planejamento, realização e avaliação desses cursos, ficando esses últimos apenas na condição de ouvintes, podem terminar por não repercutir em resultados nas práticas do professor e, do mesmo modo, não alteram sequer os discursos desses professores sobre suas práticas educativas.

Os professores precisam, eles próprios, perceber e compreender a necessidade de 
formação. Além disso, é a partir de suas percepções que se podem extrair os referenciais para pensar as políticas e os processos de desenvolvimento profissional docente. Sem esse ponto de partida focado nas experiências do cotidiano da prática educativa do professor, corre-se o risco de as políticas não resultarem em melhorias nem para o professor, nem para os estudantes matriculados nas escolas onde estes atuam.

\section{O desenvolvimento profissional docente e a melhora da escola}

Os anos 1990 foram marcados por importantes reformas educacionais na região latino-americana. Essas reformas ocorreram em um escopo mais amplo de tentativa de reestruturação do Estado e tiveram uma forte orientação de organismos internacionais, tais como o Banco Mundial. Tais reformas tiveram como foco estratégico a realização de programas de formação de professores em distintas realidades nacionais. No contexto do nordeste brasileiro, tal política se deu por meio do chamado Projeto Nordeste promovido pelo Banco Mundial (BANCO MUNDIAL, 1993; 1994). Esse projeto, entre outros objetivos, visava à realização do treinamento em serviço para professores, com vista à melhoria da qualidade da educação em face da defasagem do processo educacional da região na década em questão.

No entanto, ao se analisar as capacitações (ou cursos de capacitação) dos professores ocorridas nos anos 1990, observa-se que estas não tiveram grande impacto sobre a realidade e não conseguiram atingir o conjunto dos professores mesmo que de forma indireta. $\mathrm{Ou}$ seja, alguns professores eram escolhidos para participar das capacitações como representantes de sua escola (ou de seu município) com o compromisso de, ao retornarem para seu local de trabalho, repassarem o curso para os colegas professores.

Vários foram os obstáculos que comprometeram os resultados do programa. Dentre eles o fato de que os professores realizavam seus cursos em serviço, por isso eram oferecidos de forma aligeirada, com baixa carga horária, apenas alguns elementos dos conteúdos abordados. Além disso, muitos dos professores que participavam não possuiam formação inicial em nível superior, nem curso de licenciatura, o que dificultava o acompanhamento dos conteúdos. Da mesma forma, é impossível afirmar que esses professores tinham, por consequência, condições (do ponto de vista do conteúdo e da metodologia) de realizar o repasse do curso para os colegas ao retornarem para suas escolas/ municípios. Certamente, trata-se de aspectos da formação continuada de professores no âmbito das ações do Projeto Nordeste que carecem de um estudo mais aprofundado.

Essa prática de formação continuada de professores se constituía numa (estratégia) política de governo, marcada por uma necessidade de apresentar para a população alguma iniciativa que demarcasse uma preocupação com o setor educacional. Mas foram realizadas, na sua maioria, como programas especiais e não como políticas regulares, o que fez com que se caracterizassem como políticas de governo e não políticas de Estado.

Entretanto, isso não é uma exclusividade das políticas educacionais brasileiras. A respeito da transitoriedade das políticas educacionais de governo, Olivé (2009) aponta que:

La necesidad política de ofrecer resultados prontos y evidentes, en países donde las políticas educativas de Estado son prácticamente inexistentes y sostener políticas de gobierno que alcancen su término es un triunfo, contribuyó a convertir a la ya por sí corta premisa de la capacitación en algo aún más estrecho: una oferta de cursos. (OLIVÉ, 2009, p. 80).

0 mesmo autor ressalta que, muitas vezes, os professores até aprendem nos cursos e capacitações, mas não conseguem levar essa aprendizagem para as suas salas de aula, nem 
estender, assim, os resultados das capacitações aos seus alunos na escola básica. Há distância entre os estudos desenvolvidos nas capacitações e os problemas cotidianos da sala de aula, bem como uma grande dificuldade para o professor desenvolver uma prática pedagógica modificada pelo conhecimento obtido/construído nas capacitações em uma escola com tradições que não favorecem a educação pautada em pressupostos inovadores.

Entendendo-se que os professores e suas práticas educativas não foram considerados, nessas reformas, como ponto de partida ou como referenciais para a elaboração dos processos formativos dos professores, torna-se mais evidente o pouco efeito que esses programas tiveram. Do mesmo modo, não é difícil perceber as razões por que os possíveis desdobramentos desses cursos/ capacitações, em termos de aprendizagem conceitual e metodológica pelos professores envolvidos, são comprometidos, como também é afetada a melhoria nos resultados esperados para os estudantes da escola básica.

Não se pode deixar de considerar nessa discussão sobre a formação do professor e os desdobramentos desta na prática educativa outro aspecto que tem dificultado o desenvolvimento de um trabalho docente de qualidade na educação básica, o qual está ancorado na conjunção de três fatores. De um lado, a diversidade de acontecimentos do cotidiano escolar, como violência, participação familiar na vida estudantil dos alunos (ou a falta dela), que tem implicações diretas para o desenvolvimento profissional docente, para o empenho do professor na dupla tarefa de ensinar e também de aprender mais. Depois, o acúmulo de atividades a serem desenvolvidas pelo professor em resposta às diversas demandas sociais, considerando, inclusive, que a escola tem respondido, cada vez mais, por funções antes de responsabilidade da família. E, por fim, os padrões de poder que engessam a escola em função de burocracias administrativas.

Mesmo ponderadas todas as questões que implicam a formação docente aqui expos- tas, há que se reconhecer que todo e qualquer programa ou política de formação para o desenvolvimento profissional docente deve levar em conta as possibilidades de ocorrer, também, o desenvolvimento da aprendizagem pelos estudantes da educação básica, em primeira instância, e da sociedade, de forma mais abrangente, como resposta da escola aos investimentos financeiros, de tempo e de esforços por parte dos estudantes, dos pais destes e da sociedade, em última instância.

El desarrollo profesional docente tiene como fin mejorar el conjunto de competencias intelectuales, personales, sociales y técnicas (capacidades de lograr) que se ponen en juego para que los estudiantes de una escuela aprendan (lo que deseamos lograr). (OLIVÉ, 2009, p. 85).

A qualificação do professor com boa formação inicial e bom programa de formação continuada é extremamente necessária. Mas é preciso, igualmente, melhorar os resultados de sua ação profissional, os quais são observados pelos níveis de aprendizagem apresentados pelos estudantes. Ou seja, para tratar de formação e desenvolvimento profissional docente, deve-se levar em conta, também, o desenvolvimento discente e social.

Para tanto, algumas condições são essenciais, como tempo, espaço e recursos pedagógicos, com vistas ao professor aprender e promover, coletiva e individualmente, inovações nos conteúdos e novas formas de ensiná-los aos estudantes, de modo a incentivá-los (os estudantes) no desejo de aprender. É necessário apoio sistemático de outros profissionais da educação que dão suporte ao trabalho do professor, além das condições sociais favoráveis, com valorização do trabalho docente, compreendida como condições adequadas de trabalho, incentivo à carreira e à formação e remuneração salarial compatível, e da escola como um todo, de modo que a ambiência nos contextos em que se inserem colabore para que 
as pessoas atribuam a ela um respeito coletivo, que contribua para elevar sua importância.

Evidentemente, tudo isso demanda políticas públicas preocupadas com a existência de uma educação básica de qualidade e que ultrapassem os discursos nos palanques partidários para a efetiva realização nos sistemas educacionais dos municípios, dos estados e da união. No caso brasileiro, o compromisso com o cumprimento das metas e estratégias do Plano Nacional de Educação, Lei 13.005/2014 (BRASIL, 2014), para os próximos dez anos, é fundamental.

É possível concordar que o docente deve apresentar uma qualificação condizente com as exigências do trabalho na educação, e que essa qualificação possui forte influência na aprendizagem dos estudantes, o que implica, nesse sentido, a atualização constante. Entretanto, não se pode crer, como afirma Oliveira (2009), que tal fator seja preponderante (ou suficiente) para os bons resultados na educação básica e que os maus resultados alcançados pelos estudantes nas avaliações aplicadas pelos órgãos governamentais sejam atribuídos, de forma exclusiva, à qualificação docente.

La idea de que la mejora del desempeño de los alumnos es un factor dependiente casi exclusivamente de la calidad docente ha llevado a que los problemas de aprendizaje se justifiquen en la baja cualificación profesional de los docentes. Esto da como resultado un proceso de culpabilización de los propios profesores por el fracaso de la educación y de responsabilización de estos por mejorar su capacitación mediante iniciativas de formación. (OLIVEIRA, 2009, p. 100).

Por isso mesmo, deve haver políticas públicas de formação inicial e continuada dos professores que expressem de forma clara suas estratégias de efetivação, a fim de permitir aos professores estar sempre ampliando as suas possibilidades de enfrentamento dos diversos problemas inerentes à ação de ensinar. Mas a formação do professor, embora indispensável, não é suficiente para garantir bons resultados em termos de aprendizagem dos estudantes, também não se pode descuidar das condições de trabalho de realização do ensino-aprendizagem e das definições essenciais em relação à carreira, valorização e salários.

Pensar sobre a melhoria da educação escolar implica colocar no centro das preocupações das políticas educacionais elementos mais conceituais, capazes de operar mudanças tanto nos resultados da escolarização (a afetiva aprendizagem pelos alunos) como na constituição de uma cultura geral de valorização, não apenas da profissão do professor mas também da própria atividade da escola como um todo.

Disponibilizar livros didáticos (muitas vezes selecionados e distribuídos verticalmente de acordo com a escolha das instâncias governamentais e não com base no entendimento do professor) e demais materiais pedagógicos, tomados como a contrapartida governamental para enfrentar os baixos índices de aprendizagem pelos estudantes, não é suficiente para constituir na sociedade uma compreensão da importância da escola como instituição e da escolarização como valor social necessário. Essas estratégias, largamente utilizadas hoje por municípios e estados brasileiros, terminam por desrespeitar a autonomia garantida na LDB 9394/96 de que cada escola desenvolva de forma coletiva seu projeto pedagógico com o envolvimento da comunidade. Essa é uma conquista no sentido do reconhecimento da diversidade cultural de um país com as dimensões do Brasil, e que não pode ser desprezada.

Do mesmo modo, não serão resolvidos os problemas relativos à aprendizagem inserindo exames externos à escola, como a Prova Brasil, o Pisa, entre outros. Tais exames acabam, como sinaliza Oliveira (2009), determinando os currículos e provocando uma reestruturação do trabalho pedagógico.

Muitos gestores públicos tendem a atribuir os baixos índices de resultados dos alunos à falta de motivação e de compromisso 
dos professores. No entanto, ao fazê-lo, desconsideram que as condições de trabalho e, sobretudo, de remuneração desses profissionais os impelem muitas vezes a buscar outras atividades remuneradas, às vezes até informais e paralelas ao exercício da docência, como demonstram algumas pesquisas (TENTIFANFANI, 2005; OLIVEIRA; VIEIRA, 2010).

Atribuir os baixos índices de resultados dos alunos nos testes à falta de motivação e de compromisso dos professores é, no mínimo, uma atitude irresponsável. Contudo, é certo que a ausência de incentivos institucionais para o exercício da docência acaba intensificando a desmotivação do professor, o que pode causar um sentimento, nele mesmo, de que não está preparado, não reúne os conhecimentos necessários ao bom desempenho e de que falta profissionalidade suficiente para enfrentar o seu trabalho.

A participação de voluntários na escola, mesmo quando considerados especialistas em educação, mas que não conhecem a realidade do cotidiano da escola, acrescida à gestão da educação por pessoas que não são da área de educação podem também estar a serviço de desvalorizar o conhecimento próprio do saber prático do professor, que está inserido no ambiente da escola, em geral, e da sala de aula, de modo específico.

Outro fator agravante da situação profissional do professor diz respeito aos modismos pedagógicos, os quais terminam por obrigar o professor a romper com suas rotinas e passar a desenvolver outras práticas para as quais não se encontra preparado (NÓVOA, 2000).

Na legislação brasileira está previsto que o professor não só assuma a gestão e o desenvolvimento do trabalho pedagógico em sala de aula junto a seus alunos, mas participe, ainda, da gestão da escola, conforme estabelecem os artigos 12, 13 e 14 da LDBEN (BRASIL, 1996). À essa previsão legal deveria corresponder condições de trabalho adequadas ao desenvolvimento de atividades coletivas, que pudessem promover relações mais colaborativas no contexto escolar, contudo, a desigualdade que marca as condições de oferta da educação básica pública no Brasil tem feito com que este horizonte ainda esteja distante. Os dados do Censo Escolar demonstram como a infraestrutura das escolas básicas continua a ser um problema a enfrentar. Sem contar, como já mencionado, a dificuldade por parte dos professores de se envolverem nos coletivos escolares, pelo fato de que acumulam outros trabalhos em função dos baixos salários que recebem, como já mencionado.

A maior participação que o professor é convidado a ter na gestão da escola, em muitos casos, não é exatamente sinônimo da autonomia que o trabalho pedagógico demanda. A autonomia a que muitos professores almejam diz respeito à:

[...] liberdad para organizar su trabajo y administrar su tiempo, es decir, a tener um mayor control sobre el processo del trabajo y a obtener um mejor estatus professional. (OLIVEIRA, 2009, p. 105-106).

Quando se trata de participação na gestão dos serviços públicos, observa-se que o modelo de autonomia na gestão da escola e na gestão do trabalho pedagógico é marcado por maior responsabilização dos implicados no processo. Assim, a ideia de autonomia na gestão dos recursos é, paradoxalmente, confundida com controle e regulação da autonomia que as políticas públicas atribuem aos envolvidos. $\mathrm{Ou}$ seja, a autonomia que tais políticas conferem aos professores é muito diferente daquela desejada por eles e demarcada pelos sindicatos que os representam.

\section{Considerações finais}

Ao procurar estabelecer uma análise acerca da profissão docente no contexto social contemporâneo, este artigo tomou como foco de discussão quatro elementos, os quais são centrais para o exercício profissional docente: 
trabalho, carreira, políticas de formação/ desenvolvimento profissional docente e a prática educativa.

Observando-se o contexto de muitas mudanças vividas nas últimas décadas, o artigo procurou analisar algumas implicações e exigências de tais mudanças para o exercício da profissão docente. Nesse contexto, evidenciou-se a necessidade de maior articulação entre as políticas públicas e o trabalho docente, de modo que o professor não seja responsabilizado pelo fracasso ou sucesso da aprendizagem dos estudantes. As transformações por que vêm passando as sociedades demandam uma escola cada vez mais atenta para as necessidades de seu tempo, com desenvolvimento profissional do professor e com qualidade das condições de exercício da docência, tanto no que tange aos recursos materiais como no que diz respeito aos modos de organização e gestão do ensino e da escola.

Para tanto, faz-se imperiosa e urgente a constituição de políticas públicas que ultrapassem as barreiras dos programas dos diferentes governos e se estabeleçam como políticas de Estado voltadas para atender às diversas demandas do setor educacional. Nesse sentido, ressalta-se a importância que a questão docente tem no atual PNE, sendo tratada, diretamente, em quatro de suas vinte metas e, indiretamente, quase na sua totalidade. Essas metas, se de fato concretizadas, podem fazer a diferença no que se refere à organização da carreira docente, de modo que os profissionais possam não apenas passar por processos de desenvolvimento na profissão, mas também, em decorrência disso, galgar posições de respeito, respaldo social e retorno financeiro pelo esforço e dedicação à educação, além dos frutíferos desdobramentos em termos de aprendizagem pelos estudantes.

Desse modo, este texto ressalta que tanto as definições acerca do trabalho docente como a busca por definições claras da constituição da carreira e do desenvolvimento profissional somente fazem sentido se os objetivos do professor, da escola e dos sistemas educacionais como um todo estiverem voltados para a melhoria da qualidade da aprendizagem pelos estudantes. Entretanto, é preciso reconhecer que a qualidade esperada está diretamente relacionada com o avanço social que tais estudantes possam apresentar, em face daquilo que aprenderam na experiência de se matricular e estudar durante toda a educação básica, bem como com o seu desenvolvimento como sujeito histórico, capaz de compreender o seu tempo, sua cultura, seu ambiente e interpretá-lo. 


\section{Referências}

BANCO MUNDIAL. Acordo de empréstimo entre a República Federativa do Brasil e o Banco Internacional para Reconstrução e Desenvolvimento: terceiro projeto nordeste de educação básica: Washington, D. C.: Banco Mundial, 1994.

BANCO MUNDIAL. Staff appraisal report: segundo projeto nordeste de educação básica. Washington: Banco Mundial, 1993.

BARBOSA FILHO, Fernando de Holanda; PESSÔA, Samuel de Abreu; AFONSO, Luís Eduardo. Um estudo sobre os diferenciais de remuneração entre os professores das redes pública e privada de ensino. Estudos Econômicos. São Paulo, v. 39, n. 3, p. 597628, jan./set. 2009. Disponível em: <http://www.scielo.br/pdf/ee/v39n3/v39n3a06.pdf>. Acesso em: 11 jan. 2015.

BRASIL. Lei n. 9.394. Diretrizes e Bases da Educação Nacional. Brasília, DF: [s. n.], 1996.

BRASIL. Lei n. 13.005. Plano Nacional de Educação. Brasilia, DF: [s. n.], 2014.

CANDAU, Vera Maria (Org.). A didática em questão. Petrópolis: Vozes, 1983.

DUARTE, Alexandre William Barbosa. Por que ser professor? Uma análise da carreira docente na educação básica no Brasil. 2012. 169f. Dissertação (Mestrado em Educação) - Faculdade de Educação da Universidade Federal de Minas Gerais, Belo Horizonte, 2013.

ESTEVE, José Manoel. Escenarios del presente e interrogantes para la construcción del futuro. In: MEDRANO, Consuelo Vélez de; VAILLANT, Denise. Aprendizaje y desarrollo profesional docente. Madrid: Santillana, 2009. p. 17-27.

GATTI, Bernardete Angelina; BARRETO, Elba Siqueira de Sá (Coord.). Professores do Brasil: impasses e desafios. Brasília, DF: Unesco, 2009.

GATTI, Bernardete Angelina; BARRET0, Elba Siqueira de Sá; ANDRÉ, Marli Eliza Dalmazo de Afonso (Coord.). Políticas docentes no Brasil: um estado da arte. Brasília, DF: Unesco, 2011.

JACOMINI, Márcia Aparecida; MINHOTO. Maria Angélica Pedra. Remuneração dos docentes da rede municipal de são Paulo (1996-2010): considerações preliminares. In: CONGRESSO IBERO AMERICANO DE POLÍTICA DE ADMINISTRAÇÃO DA EDUCAÇÃO, 3., 2012. Anais. Zaragoza: [s. n.], 2012. Disponível em: <http://www.anpae.org.br/iberoamericano2012/Trabalhos/ MarciaAparecidaJacomini_res_int_GT6.pdf>. Acesso em: 09 jan. 2015.

LEME, Luciana França. Atratividade do magistério para 0 ensino básico: estudo com ingressantes de cursos superiores da Universidade de São Paulo. 2012. 192 f. Dissertação (Mestrado em Educação) - Faculdade de Educação da Universidade de São Paulo. São Paulo, 2012.

MARCELO, Carlos. La evaluación del desarrollo profesional docente. In: MEDRANO, Consuelo Vélez de; VAlLLANT, Denise. Aprendizaje y desarrollo profesional docente. Madrid: Santillana, 2009. p. 119-127.

MORICONI, Gabriela Miranda. Os professores públicos são mal remunerados nas escolas brasileiras? Uma análise da atratividade da carreira do magistério sob 0 aspecto da remuneração. 2008. 82 f. Dissertação (Mestrado em Administração Pública e Governo) - Escola de Administração de Empresas de São Paulo, Fundação Getúlio Vargas. São Paulo, 2008.

NÓVOA, Antonio. Os professores e a história da sua vida. In: NÓVOA, António (Org.). Vida de professores. 2. ed. Porto: Porto, 2000. p. 11-30.

NÓVOA, Antonio. Profesores: el futuro aún tardará mucho tempo? In: MEDRANO, Consuelo Vélez de; VAILLANT, Denise. Aprendizaje y desarrollo profesional docente. Madrid: Santillana, 2009. p. 49-55.

OLIVÉ, Alba Martínez. El desarrollo profesional docente y la mejora de la escuela. In: MEDRANO, Consuelo Vélez de; VAILLANT, Denise. Aprendizaje y desarrollo profesional docente. Madrid: Santillana, 2009. p. 79-88.

OLIVEIRA, Dalila Andrade. Modelos y estrategias de desarrollo profesional docente: reflexiones críticas desde la realidad lationoamericana. In: MEDRANO, Consuelo Vélez de; VAILLANT, Denise. Aprendizaje y desarrollo profesional docente. Madrid: Santillana, 2009. p. 99-107. 
OLIVEIRA, Dalila Andrade. Pesquisa trabalho docente na educação básica no Brasil: sinopse do survey nacional. GESTRADO: Grupo de Estudos sobre Políticas Educacionais e Trabalho Docente. Belo Horizonte: [s. n.], 2010. Disponível em:<www. trabalhodocente.net.br>. Acesso em: 07 ago. 2015.

RAMALHO, Betânia Leite; NUNEZ, Isauro Beltran; GAUTHIER, Clermont. Formar o professor, profissionalizar 0 ensino: perspectivas e desafios. 2. ed. Porto Alegre: Sulinas, 2004.

TERIGI, Flavia. Carrera docente y políticas de desarrollo profesional. In: MEDRANO, Consuelo Vélez de; VAILLANT, Denise. Aprendizaje y desarrollo profesional docente. Madrid: Santillana, 2009. p. 137-147.

TENTI FANFANI, Emílio. La condición docente: análisis comparado de la Argentina, Brasil, Perú y Uruguay. Buenos Aires: Siglo XXI, 2005.

VAILLANT, Denise. Políticas para un desarrollo profesional docente efectivo. In: MEDRANO, Consuelo Vélez de; VAlLLANT, Denise. Aprendizaje y desarrollo profesional docente. Madrid: Santillana, 2009. p. 29-37.

Recebido em: 30.01.2015.

Aprovado em: 22.09.2015

Claudio Pinto Nunes é professor titular do programa de pós-graduação em Educação da Universidade Estadual do Sudoeste da Bahia. É coordenador de gestão do Programa Institucional de Bolsa de Iniciação à Docência (Pibid) e líder do Grupo de Pesquisas sobre Didática, Formação e Trabalho Docente (Difort/CNPq).

Dalila Andrade Oliveira é professora titular da Faculdade de Educação e do Programa de Pós-Graduação em Educação da Universidade Federal de Minas Gerais na área de Políticas Públicas e Educação. É coordenadora geral da Rede latinoamericana de Estudos sobre o Trabalho Docente (RedEstrado) e líder do Grupo de Estudos sobre Política Educacional e Trabalho Docente (Gestrado/CNPq). 